\title{
Septoplastide Transseptal Sütür, Nazopor ve Splint Kullanımının Karşılaşıııılması
}

\author{
Gülpembe Bozkurt ${ }^{1}$, Eymen Oruç ${ }^{2}$, Arzu Yasemin Korkut ${ }^{1}$, Berna Uslu Coşkun ${ }^{1}$
}

\begin{abstract}
ÖZET:
Septoplastide transseptal sütür, nazopor ve splint kullanımının karşıllaştırılması

Amaç: Septoplasti sonrası havayollu internal nazal splint, sentetik poliüretan tampon (nazopor) ve transseptal sütür tekniğinin hasta yakınmaları ve konforu üzerine etkilerini ve oluşabilecek komplikasyonları karşılaştırmak amacıyla yapılan prospektif randomize çalışma.

Gereç ve Yöntemler: Septoplasti operasyonu uygulanan 60 hasta randomize bir şekilde 20'şer hastadan oluşan 3 gruba ayrıldı. Postoperatif olarak Grup I'dekilere havayollu internal nazal splint, Grup II'dekilere sentetik poliüretan tampon yerleştirildi ve Grup III'tekilere transseptal sütür atıldı. Görsel Analog Skorlama (GAS) ile postoperatif subjektif şikayetıer (ağrı, basınç hissi, burun tıkanıklığı, anterior rinore, postnazal akıntı, disfaji, uyku bozukluğu) ve muayene ile sineşi, kanama, septal enfeksiyon, hematom, perforasyon mevcudiyeti değerlendirildi.

Bulgular: Grup II'de postnazal akıntı yakınması, Grup I'den anlamlı ( $p<0.05)$ olarak yüksek bulundu. Grup III'te ise postnazal akıntı yakınması Grup I ve Grup II'den anlamlı (p>0.05) farklılık göstermedi. Grup II'de basınç yakınması Grup III'ten anlamlı (p<0.05) olarak yüksek bulundu. Grup I'de ise basınç yakınması Grup II ve Grup III'ten anlamlı (p>0.05) farklılık göstermedi. Hastaların ağrı, burun tıkanıklığı, anterior rinore, disfaji, uyku bozukluğu yakınmaları anlamlı (p>0.05) farklılık göstermedi. Postoperatif komplikasyonlar açısından üç grupta da istatistikselolarak anlamlı farklılık görülmedi ( $p>0.05$ ).

Sonuç: Sentetik poliüretan tampon, internal nazal splint ve transseptal sütür yöntemi ile karşılaştırıldığında hasta konforunu arttırmadığı, postoperatif komplikasyonlar açısından anlamlı bir farklılık oluşturmadığı ve daha yüksek maliyetli olduğu için, daha düşük maliyetli olan internal nazal splint ve transseptal sütür yöntemi tercih edilebilir.
\end{abstract}

Anahtar kelimeler: Nazal splint, nazopor, transseptal sutur

\section{ABSTRACT:}

Comparison of nasal airway splint, synthetic polyurethane foam (nasopore) and transseptal suture technique in septoplasty

Objective: A prospective randomised study for comparison of the efficacy and possible complications of nasal airway splint, synthetic polyurethane foam (nasopore) and transseptal suture technique in septoplasty.

Material and Methods: 60 patients underwent septoplasty for septal deviation. These patients were divided into three groups: nasal airway splint (using intranasal septal splints at the end of the operation) (Group I), nasopore (using nasopore packing at the end of the operation) (Group II) and non-packing (using separate trans-septum through and through horizontal mattress sutures without any mesh or intranasal splint insertion) (Group III). Patients were asked to record pain levels using a visual analogue scale. The three groups were compared for postoperative subjective complaints (pain, pressure sensation, nasal congestion, anterior rhinorrhea, postnasal drip, dysphagia, sleep disorder) and complications (perforation, hematoma, infection, synechiae, postoperative bleeding).

Results: There were no significant statistical differences between the three groups with respect to the complication parameters studied, but higher postnasal drip levels in Group II compared to the Group I and also no statistical differences in the other parameters (pain, nasal congestion, anterior rhinorrhea, dysphagia, sleep disorder) were found.

Conclusion: Our results suggest that nasopore insertion did not benefit more than those who had trans-septum through and through suturing and intranazal splint. Moreover, internal nazal splint and tansseptal suture technique is much preferable because of the higher cost of nasopore.

Keywords: Nasal splint, nasopore, transseptal suture

Ş.E.E.A.H. Tıp Bülteni 2016;50(2):110-4
'Şişli Hamidiye Etfal Eğitim ve Araştıma Hastanesi, Kulak Burun Boğaz Kliniği, İstanbul - Türkiye

${ }^{2}$ Araklı Devlet Hastanesi, Trabzon - Türkiye

Yazışma Adresi / Address reprint requests to: Gülpembe Bozkurt,

Şişli Hamidiye Etfal Eğitim ve Araştırma Hastanesi, Kulak Burun Boğaz Kliniği,

İstanbul, Türkiye

E-posta / E-mail: gptalayhan@gmail.com

Geliş tarihi / Date of receipt: 15 Şubat 2016 / February 15, 2016

Kabul tarihi / Date of acceptance: 1 Nisan 2016 / April 1, 2016 


\section{GíRiş}

Septal deviasyon, pratik tababette kulak burun boğaz doktorunun en sık karşılaştığı patolojilerden biridir. Septal deviasyonların sebep olduğu obstrüktif etkinin ortadan kaldırılması amacıyla hastalara çeşitli septal cerrahi teknikleri uygulanmaktadır. Bu tekniklerden en yaygın olanlarından biri septoplasti ameliyatıdır. Intranazal tamponlar, cerrahi sonrasında septal hematomu önlemek, destek sağlamak, kanama kontrolü sağlamak, sineşileri önlemek, eleve edilen mukoperikondriyal dokuların yerine oturmasına yardımcı olmak amacıyla kullanılmaktadır. Nazal tamponlara bağlı çeşitli sorunların olabileceği de bilinmektedir. Bunlar arasında, septum perforasyonu, alt konka nekrozu (1), piyojenik granülom (2), hayatı tehdit eden toksik şok sendromu (3), tıkayıcı uyku apnesi (4), oksijen satürasyonunda azalma ve kalp hızında artma (5), ağrı $(6,7)$ sayılabilir.

Postseptoplasti hastalarında nazal tamponlarla ilgili bildirilen en sık morbidite ağrıdır $(8,9)$. Ek olarak, tıkayıcı uyku apne sendromu, kalp hastalığı, kronik obstruktif akciğer hastalığı bulunan yaşlı hastalarda uyku sırasında hiperkapni ve hipoksiye sebep olma riski nedeniyle, bu grup hastalarda nazal tamponların kullanımına dikkat edilmelidir $(10,11)$. Tamponların istenmeyen etkilerinden kaçınmak amacıyla, farklı yapı ve şekillerde nazal tampon yerleştirilmesi veya hiç tampon uygulanmaması ya da alternatif olarak giderek artan sıklıkta septal sütürasyon uygulamaları yapılmaktadır $(12,13)$.

Bu çalışma, septoplasti ameliyatı sonrası kullanılan havayollu internal nazal splint (ENT Med, İstanbul, Türkiye), sentetik poliüretan tampon (Nasopore; Polyganics BV, Groningen, Hollanda) ve tampon konulmaksızın transseptal sütür atma tekniğinin hasta yakınmaları ve hasta konforu üzerine etkilerini ve oluşabilecek komplikasyonları karşılaştırmak amacıyla yapılmıştır.

\section{GEREÇ VE YÖNTEMLER}

Bu prospektif randomize çalışma Şişli Hamidiye Etfal Kulak Burun Boğaz polikliniğine başvurup septum deviasyonu tanısı alan, Haziran 2013 ile Kasım 2013 tarihleri arasında Şişli Hamidiye Etfal Eğitim ve
Araştırma Hastanesi Etik Kurulu'nun onayı alınarak septoplasti operasyonu uygulanan 60 hastayı içermektedir. Ameliyat öncesi yapılacak işlemler konusunda tüm hastalar ayrıntılı bir şekilde bilgilendirilip, ayrıntılı onamları alındı.

Hastaların ayrıntılı anamnezleri sorgulandı ve rutin KBB muayenesi ile birlikte endoskopik nazal muayene yapıldı. Aterosklerotik kalp hastalığı, diabetes mellitus, hipertansiyon, malignite, koagülopati vb ciddi sistemik hastalıklar, alerji, astım hastalığı, nazal polip, aspirin intoleransı, daha önce geçirilmiş burun ameliyatı, alt konka hipertrofisi gibi septum deviasyonu dışındaki sinonazal patolojiler çalışmaya dahil edilmeme kriterleri olarak belirlendi. Çalışmaya dahil edilen 60 hastaya genel anestezi altında Cottle tekniği ile septoplasti operasyonu uygulandı. Operasyon sonunda hastalar rastgele olacak şekilde, postoperatif nazal tampon olarak havayollu internal nazal splint kullanılan hastalar (Grup I), postoperatif nazal tampon olarak nazopor kullanılan hastalar (Grup II) ve postoperatif nazal tampon yerine transseptal sütür atılan hastalar (Grup III) olmak üzere 20 'şer hastadan oluşan 3 gruba ayrıldı.

Tüm hastalara genel anestezi altında aynı cerrah tarafından Cottle tekniği ile septoplasti ameliyatı uygulandı. Bunun haricinde hiçbir hastaya alt konkaya yönelik herhangi bir cerrahi işlem uygulanmadı. Hastaların gruplara dağılımı operasyon sonunda ameliyathane salonunda bulunan ikinci bir cerrah tarafından rastgele seçilerek karar verildi. Hasta takip formu oluşturularak operasyon süresi, oluşan mukozal kopma, kullanılan nazal tampon çeşidi ve yöntemi kaydedildi. Postoperatif 48. saatte nazal tamponlar çekildi ve bütün hastalara subjektif şikayetlerinin (ağrı, basınç hissi, burun tıkanıklığı, anterior rinore, postnazal akıntı, disfaji, uyku bozukluğu ve sadece Grup I ile Grup II hastalarına nazal tamponlar çıkarılırken oluşan ağrı şiddeti) değerlendirilmesi amacıyla Görsel Analog Skorlama (GAS) uygulandı, yakınmalar 1'den 10`a kadar numaralandırılarak yakınmaların şiddeti hafiften ağıra doğru derecelendirildi. Bütün hastalar postoperatif 2. gün, 1 . ve 4 . hafta poliklinik kontrolüne çağırılarak anterior rinoskopi ve 0 derece rigid endoskop ile nazal muayeneleri yapıldı. Septal enfeksiyon, septal hematom, septal perforasyon, sineşi, kanama açısından hastalar değerlendirildi. 


\section{İstatistiksel Yöntem}

Verilerin tanımlayıc istatistiklerinde ortalama, standart sapma, medyan, minimum-maksimum, oran ve frekans değerleri kullanılmıştır. Değişkenlerin dağılımı Kolmogorov Simirnov testi ile kontrol edildi. Postoperatif ölçümlerde niceliksel verilerin analizinde ANOVA (Tukey test) kullanıldı. Oransal kıyaslamalarda (niteliksel verilerin analizinde) ki-kare test kullanıldı. Ki- kare test koşulları sağlanamadığında Fischer testi kullanıldı. İstatistiksel analizlerde SPSS 22.0 (IBM Corp; Armonk, New York, ABD) programı kullanılmıştır.

\section{BULGULAR}

Grup I'de yer alan 20 hastaya (14 erkek, 6 kadın; yaş aralığı 18-57; yaş ort. $31.9 \pm 12.8$ ) postoperatif nazal tampon olarak havayollu internal nazal splint uygulandı. Grup II'de yer alan 20 hastaya (14 erkek,

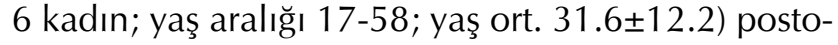
peratif nazal tampon olarak nazopor uygulandı. Grup III'te yer alan 20 hastaya (14 erkek, 6 kadın; yaş aralığı 18-53; yaş ort. 30.0ะ10.7) postoperatif transseptal sütür tekniği uygulandı. Grup I, Grup II ve Grup III'te yer alan hastaların yaşları, cinsiyet dağılımı anlamlı ( $p>0.05$ ) farklılık göstermemiştir (Tablo- 1 ).

Grup II'de postnazal akıntı yakınması, Grup I'den anlamlı ( $p<0.05)$ olarak yüksek bulunmuştur. Grup III'te ise postnazal akıntı yakınması Grup I ve Grup II'den anlamlı ( $p>0.05)$ farklılık göstermemiştir. Grup II'de basınç yakınması Grup III'ten anlamlı $(p<0.05)$ olarak yüksek bulunmuştur. Grup I'de ise basınç yakınması Grup II ve Grup III'ten anlamlı ( $p>0.05$ ) farklılık göstermemiştir. Grup I, Grup II ve Grup III'te yer alan hastaların ağrı, burun tıkanıklığı, anterior rinore, disfaji, uyku bozukluğu yakınmaları anlamlı ( $p>0.05$ ) farklılık göstermemiştir. Grup I ve Grup II'de yer alan hastalarda tampon çıkarılırken oluşan ağrı yakınması anlamlı ( $p>0.05)$ farklılık göstermemiştir.

Tablo-1: Grup I, Grup II ve Grup III'te yer alan hastaların yaş ve cinsiyet dağılımı

\begin{tabular}{|c|c|c|c|c|c|c|c|c|c|}
\hline & & & & Grup I & & Grup II & & Grup III & p \\
\hline \multirow[t]{2}{*}{ Yaş } & & Ort \pm S.S. & & $31.9 \pm 12.8$ & & $31.6 \pm 12.2$ & & $30.0 \pm 10.7$ & 0.863 \\
\hline & & Med (Min-Mak) & 29 & $18-57$ & 29 & $17-58$ & 27 & $18-53$ & \\
\hline \multirow[t]{2}{*}{ Cinsiyet } & Kadın & $n-\%$ & & $6-\% 30$ & & $6-\% 30$ & & $6-\% 30$ & 1.000 \\
\hline & Erkek & $n-\%$ & & $14-\% 70$ & & $14-\% 70$ & & $14-\% 70$ & \\
\hline
\end{tabular}

ANOVA/ Ki-kare test, Ort: Ortalama, S.S.: Standard Sapma, Med: Median, Min: Minimum, Mak: Maksimum

Tablo-2: Grup I, Grup II ve Grup III'te yer alan hastaların GAS cetveli sonuçları

\begin{tabular}{|c|c|c|c|c|c|c|c|c|}
\hline & & & Grup I & & Grup II & & Grup III & $\mathbf{p}$ \\
\hline \multirow[t]{2}{*}{ Ağrı } & Ort. \pm S.S. & & $3.8 \pm 2.9$ & & $3.3 \pm 1.9$ & & $3.9 \pm 2.1$ & 0.658 \\
\hline & Med (Min-Mak) & 3 & $0-10$ & 3 & $0-6$ & 4 & $0-10$ & \\
\hline \multirow[t]{2}{*}{ Basınç } & 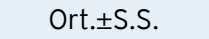 & & $3.5 \pm 2.9$ & & $4.9 \pm 2.3$ & & $2.4 \pm 2.2$ & 0.011 \\
\hline & Med (Min-Mak) & 3 & $0-9$ & 5 & $0-8$ & 3 & $0-7$ & (Grup II>Grup III) \\
\hline \multirow[t]{2}{*}{ Burun Tıkanıklığı } & Ort. \pm S.S. & & $5.3 \pm 2.9$ & & $6.2 \pm 2.4$ & & $6.0 \pm 2.3$ & 0.506 \\
\hline & Med (Min-Mak) & 5 & $2-10$ & 6 & $1-10$ & 6 & $2-10$ & \\
\hline \multirow[t]{2}{*}{ Anterior Rinore } & Ort. \pm S.S. & & $4.9 \pm 2.5$ & & $5.8 \pm 2.6$ & & $5.9 \pm 2.9$ & 0.447 \\
\hline & Med (Min-Mak) & 5 & $0-10$ & 6 & $0-10$ & 5 & $1-10$ & \\
\hline \multirow[t]{2}{*}{ Postnazal Akıntı } & Ort. \pm S.S. & & $2.9 \pm 2.5$ & & $5.3 \pm 3.2$ & & $3.7 \pm 2.8$ & 0.032 \\
\hline & Med(Min-Mak) & 3 & $0-7$ & 6 & $0-10$ & 4 & $0-10$ & (Grup II>Grup I) \\
\hline \multirow[t]{2}{*}{ Disfaji } & Ort. \pm S.S. & & $2.7 \pm 3.0$ & & $4.9 \pm 2.9$ & & $3.3 \pm 2.7$ & 0.054 \\
\hline & Med (Min-Mak) & 3 & $0-10$ & 5 & $0-10$ & 3 & $0-10$ & \\
\hline \multirow[t]{2}{*}{ Uyku Bozukluğu } & Ort. \pm S.S. & & $4.6 \pm 2.6$ & & $6.2 \pm 2.8$ & & $4.4 \pm 3.0$ & 0.085 \\
\hline & Med (Min-Mak) & 5 & $0-8$ & 7 & $0-10$ & 5 & $0-10$ & \\
\hline \multirow[t]{2}{*}{ Tampon Çıkarılırken Ağrı } & Ort. \pm S.S. & & $5.3 \pm 2.6$ & & $4.8 \pm 3.3$ & & & 0.561 \\
\hline & Med (Min-Mak) & 6 & $1-10$ & 4 & $0-10$ & & & \\
\hline \multirow[t]{2}{*}{ Operasyon Süresi } & Ort. \pm S.S. & & $66.5 \pm 20.5$ & & $60.4 \pm 12.4$ & & $63.6 \pm 19.4$ & 0.564 \\
\hline & Med (Min-Mak) & 60 & $40-118$ & 60 & $30-90$ & 57 & $40-118$ & \\
\hline
\end{tabular}

ANOVA (Tukey test) / Ort: Ortalama, S.S.: Standard Sapma, Med: Median, Min: Minimum, Mak: Maksimum 
Tablo-3: Grup I, Grup II ve Grup III'te yer alan hastaların postoperatif komplikasyon sonuçlarının karşılaştırılması

\begin{tabular}{|c|c|c|c|c|c|c|}
\hline & & & Grup I & Grup II & Grup III & p \\
\hline \multirow[t]{2}{*}{ Kanama } & Yok & $n-\%$ & $18-\% 90$ & $17-\% 85$ & $17-\% 85$ & 0.349 \\
\hline & Var & $n-\%$ & $2-\% 10$ & $3-\% 15$ & $3-\% 15$ & \\
\hline \multirow[t]{2}{*}{ Septal Enfeksiyon } & Yok & $n-\%$ & $19-\% 95$ & $18-\% 90$ & $20-\% 100$ & $p>0.05$ \\
\hline & Var & $n-\%$ & $1-\% 5$ & $2-\% 10$ & $0-\% 0$ & \\
\hline \multirow[t]{2}{*}{ Septal Hematom } & Yok & $n-\%$ & $20-\% 100$ & $20-\% 100$ & $20-100$ & - \\
\hline & Var & $n-\%$ & $0-\% 0$ & $0-\% 0$ & $0-\% 0$ & \\
\hline \multirow[t]{2}{*}{ Septal Perforasyon } & Yok & $n-\%$ & $20-\% 100$ & $20-\% 100$ & $20-\% 100$ & - \\
\hline & Var & $n-\%$ & $0-\% 0$ & $0-\% 0$ & $0-\% 0$ & \\
\hline \multirow[t]{2}{*}{ Sineşi } & Yok & $n-\%$ & $20-\% 100$ & $19-\% 95$ & $18-\% 90$ & $p>0.05$ \\
\hline & Var & $n-\%$ & $0-\% 0$ & $1-\% 5$ & $2-\% 10$ & \\
\hline
\end{tabular}

Ki-kare test (Fischer test)

Grup I, Grup II ve Grup III'te yer alan hastaların operasyon süreleri karşılaştıııldığında anlamlı ( $p>0.05)$ farklılık saptanmadı (Tablo-2).

Grup I'de 1 hastada postoperatif 7. günde septal enfeksiyon saptandı. Grup II'de postoperatif 7. ve 30. günde 2 hastada septal enfeksiyon, 1 hastada sineşi saptandı. Grup III'te 2 hastada sineşi saptandı. Her üç grupta septal hematom, septal perforasyon izlenmedi.

Grup I ve Grup II'de postoperatif 48. saatte nazal tamponların çekilmesinden sonra ve Grup III'te postoperatif dönemde tekrar tampon konulması gereken burun kanaması olmadı. Grup I'de 2 hasta, Grup II'de 3 hasta ve Grup III'te 3 hastada sızıntı şeklinde de olsa kanama kontrolü için geçici süre ile adrenalin emdirilmiş pamuk şeritler kullanıldıktan sonra kanama durduruldu. Postoperatif komplikasyonlar açısından bakıldığında gruplar arasında istatistiksel olarak anlamlı farklılık saptanmadı (Tablo-3).

\section{TARTIŞMA}

Septoplasti operasyonu sonrası nazal fonksiyonlar ve hastanın konforunun sağlanmasında kullanılan nazal tamponların etkisi önemlidir. Literatürde tampon konulmamasını öneren yazarlar da bulunmaktadır. Literatürde, nazal tampona alternatif olarak, septuma çeşitli tekniklerde hemostatik sütürasyon teknikleri tariflenmiştir $(14,15)$. Ancak, enfeksiyon, hematom ve perforasyon açısından anlamlı bir farklılık belirtilmemiştir.

Nazal tampon çıkarılması esnasındaki ağrı, septoplasti ve/veya septorinoplasti operasyonu uygula- nan hastalarda cerrahinin sıklıkla en rahatsız edici kısmını oluşturur (11). Septal sütürasyon uygulanımı sonrası tampon çekilme sorunu olmadığından, hastanın postoperatif konforu açısından daha iyi durumda oldukları belirtilmiştir $(8,16)$. Çalışmamızda her üç grupta ağrı ve tampon uyguladığımız gruplarda tampon çıkarılırken oluşan ağrı GAS ile değerlendirildiğinde gruplar arasında istatistiksel olarak anlamlı farklılıklar elde edilmedi. Bununla ilgili yapılan bir çalışmada Thomas ve ark. (6) 72 hastaya nazal cerrahi yapıp burun tamponu uygulamışlardır. Tamponlu bir grupta 2 saat sonra bir grupta 24 saat sonra çekmişler ve ağrı skorlamasının 2 saatlik grupta 24 saatlik gruba göre önemli ölçüde düşük çıktığını göstermişlerdir. Ardehali ve ark. (7) nın yaptığı bir çalışmada nazal tampon koyduğu ve koymadığı sadece transseptal sütür attığı hastaları karşılaştırmıştır. Tampon konulan grupta istatistiksel olarak anlamlı ağrı seviyeleri not edilmiştir.

Nazal cerrahi sonrası kullanılan tamponların burunda ne kadar süre kalacağı, endikasyonları ve ne tür bir tampon kullanılacağı ile ilgili herhangi bir ortak görüş sağlanamamıştır. Lubianca (17) yaptığı çalışmada 24 saat tampon konulması ile 48 saat tamponun konulması arasında hemorajik komplikasyonlar açısından istatistiksel fark bulmamıştır.

Çalışmamızda küçük parçacıklara ayrılmış nazopor tamponun postoperatif 2. günde, mukozal irritasyon yaratmadan aspire edilirken hastaları istatistiksel olarak anlamlı olmasa da daha rahat olduklarını gözlemledik. Kim ve ark. (18) yaptıkları çalışmada nazopor ve merosel tamponu karşılaştırmışlar, tampon çıkarılırken oluşan ağrı yakınması merosel konulan 
grupta istatistiksel olarak anlamlı derecede yüksek olduğunu göstermişlerdir. Yine bu çalışmada hasta konforu açısından nazopor tamponun meroselden istatistiksel olarak anlamlı derecede daha konforlu olduğunu göstermişlerdir.

Bu çalışmada, nazopor grubunda postnazal akıntı nazal splint grubundan, basınç hissi transseptal sütür grubundan anlamlı olarak yüksek bulundu. İnternal nazal splint ve transseptal sütür yöntemi ile karşılaştırıldığında nazopor tamponun hasta konforuna katkı sağlamadığı da göz önünde bulundurulmalıdır.

Çalışmamızda hiçbir grupta septal hematom, septal perforasyon izlenmedi. Kanama açısından gruplar değerlendirildiğinde tekrar nazal tampon uygulanan hasta olmadı, sızıntı şeklinde olan kanamalar ise adrenali emdirilmiş pamuk şeritler ile durduruldu. Kanama yönünden nazopor, internal nazal splint ve transseptal sütür yöntemlerinin birbirlerine üstünlükleri yok idi. İstatistiksel olarak

\section{KAYNAKLAR}

1. Dowley AC, Strachan DR. Allergy to merocel nasal packs causing septal perforation and inferior turbinate necrosis. J Laryngol Otol 2001; 115: 735. [CrossRef]

2. Lee HM, Lee $S H, H$ wang SJ. A giant pyogenic granuloma in the nasal cavity caused by nasal packing. Eur Arch Otorhinolaryngol 2002; 5: 231-3. [CrossRef]

3. Manstied CJ, Peterson MB. Toxic shock syndrome associated with nasal packing. Clin Pediatr (Phile) 1989; 10: 443-5.

4. Jensen PF, Kristensen S, Jull A, Johannessen N. Episodic nocturnal hypoxia and nasal packs. Clin Otolaryngol 1991; 16: 433-5. [CrossRef]

5. Öğretmenoğlu $O$, Yılmaz $T$, Rahimi $K$, Aksoyek S. The effect of arterial blood gases and heart rate of bilateral nasal packing. Eur Arch Otorhinolaryngol 2002; 259: 63-6. [CrossRef]

6. Thomas DM, Tierney PA, Samuel D, Patel KS. Audit of pain after nasal surgery. Ann R Coll Surg Engl 1996; 78: 380-2.

7. Ardehali MM, Bastaninejad S. Use of nasal packs and intranasal septal splints following septoplasty. Int J Oral Maxillofac Surg 2009; 38: 1022-4. [CrossRef]

8. Von Schoenberg $M$, Robinson $P$, Ryan R. Nasal packing after routine nasal surgery - is it justified? J Laryngol Otol 1993; 107: 902-5. [CrossRef]

9. Samad I, Stevens HE, Maloney A. The efficacy of nasal septal surgery. J Otolaryngol 1992; 21: 88-91.

10. Weber R, Keerl R, Hochapfel F, Draf W, Toffel PH. Packing in endonasal surgery. Am J Otolaryngol 2001; 22: 306-20. [CrossRef] komplikasyonlar değerlendirildiğinde anlamlı fark görülmedi.

Nazal septal cerrahi sonrası tampon kullanımı hem postoperatif kanamanın önlenmesi hem de fleplerin ve septumun stabilizasyonunun sağlanması açısından önemlidir. Çalışmamızda internal nazal splint ve transseptal sütür yöntemi ile karşılaştırıldı̆̆ında nazopor tamponun hasta konforunu arttırmaması, postoperatif komplikasyonlar açısından anlamlı bir farklılık oluşturmaması yanında daha yüksek maliyetli olması göz önünde bulundurulmalıdır. Postoperatif komplikasyonlar açısından üç grup arasında anlamlı farklılık olmasa da internal nazal splint kullanılan hastalarda postoperatif dönemde sineşi izlenmediği görülmektedir. Sonuç olarak hasta konforu ve postoperatif komplikasyonlar açısından bakıldığında septoplasti sonrası daha düşük maliyetli olan internal nazal splint kullanımının ve transseptal sütür yönteminin daha uygun olduğu kanaatindeyiz.

11. Weber R, Hochapfel F, Draf W. Packing and stents in endonasal surgery. Rhinology 2000; 38: 49-62.

12. Gottschalk GH. An improved septoplasty: the microsurgical suture technique. Ann Plast Surg 1978; 1: 30-3. [CrossRef]

13. Reiter D, Alford E, Jabourian Z. Alternatives to packing in septorhinoplasty. Arch Otolaryngol Head Neck Surg 1989; 115: 1203-5. [CrossRef]

14. Özkırış M, Kapusuz Z, Saydam L. Comparison of nasal packs with transseptal suturing after nasal septal surgery. Am J Otolaryngol 2013; 34: 308-11. [CrossRef]

15. Yildirim A, Yasar M, Bebek Al, Canbay E, Kunt T. Nasal septal suture technique versus nasal packing after septoplasty. Am J Rhinol 2005; 19: 599-602.

16. Nunez DA, Martin FW. An evaluation of post-operative packing in nasal septal surgery. Clin Otolaryngol Allied Sci 1991; 16: 549-50. [CrossRef]

17. Lubianca-Neto JF, Sant'anna GD, Mauri M, Arrarte JL, Brinckman CA. Evaluation of time of nasal packing after nasal surgery: a randomized trail. Otolaryngol Head Neck Surg 2000; 122: 899901. [CrossRef]

18. Kim YS, Kim YH, Kim NH, Kim SH, Kim KR, Kim KS. A prospective, randomized, single blinded controlled trial on biodegradable synthetic polyurethane foam as a packing material after septoplasty. Am J Rhinol Allergy 2011; 25: 77-9. [CrossRef] 